\title{
Regulatory Effects of Reboxetine Treatment Alone, or Following Paroxetine Treatment, on Brain Noradrenergic and Serotonergic Systems
}

\author{
Georgianna G Gould*,', Marie-Christine Pardon', David A Morilak' and Alan Frazer, ${ }^{1,2}$ \\ 'Department of Pharmacology, University of Texas Health Science Center at San Antonio, San Antonio, TX, USA; ${ }^{2}$ South Texas Veterans Health \\ Care System, San Antonio, TX, USA
}

\begin{abstract}
When patients do not respond to an initial antidepressant, one clinical approach is to switch to an agent in a different pharmacological class. However, few studies have examined the neurochemical consequences of this practice. To study this, we examined changes in binding sites in rat brain for norepinephrine (NET) and serotonin transporters (SERT), $\alpha_{1}, \alpha_{2}$, and $\beta_{1}$ adrenergic receptors after chronic administration of paroxetine (PRX), reboxetine (RBX), or PRX followed by RBX. We also examined the effects of these treatments on mRNA expression for tyrosine hydroxylase $(T H)$. RBX treatment for 3 weeks reduced NET binding significantly, by $\sim 40 \%$ in terminal field areas, and 6 weeks of RBX reduced it even more, by $\sim 60 \%$. RBX treatment for 3 and 6 weeks reduced $\beta_{1}$ adrenergic receptorbinding sites equally, by $50-60 \%$. At no time did RBX treatment reduce SERT-binding sites. PRX treatment had no effect on $\beta_{1}$ adrenergic or NET-binding sites, but reduced SERT-binding sites by $75-80 \%$. Neither treatment altered mRNA for TH, $\alpha_{1}$, or $\alpha_{2}$ adrenergic receptor-binding sites. When 3 weeks of RBX treatment followed 3 weeks of PRX treatment, NET-binding sites were reduced to the same extent as measured after 6 weeks of RBX treatment alone, indicating that PRX pretreatment may have 'primed' the subsequent regulatory effect of RBX on the NET. Thus, pretreatment of rats with PRX actually enhanced at least one regulatory effect of RBX treatment on the noradrenergic system, and did not interfere with any other pharmacological effect caused by RBX treatment. Neuropsychopharmacology (2003) 28, 1633-164I, advance online publication, 25 June 2003; doi:I0.1038/sj.npp. I 300236
\end{abstract}

Keywords: antidepressants; reboxetine; norepinephrine transporter; quantitative autoradiography; serotonin transporter; paroxetine

\section{INTRODUCTION}

Some patients do not respond to an initial antidepressant (AD) treatment or the treatment loses efficacy over time. Regardless of the class of AD administered, $30-45 \%$ of patients fail to respond adequately to drug treatment (Fava, 2000). One strategy that has been widely adopted for treatment of nonresponsive depressed patients is to switch from the initial type of $\mathrm{AD}$ used, such as a selective serotonin reuptake inhibitor (SSRI), to another class, such as a selective norepinephrine reuptake inhibitor (NRI) (Thase and Rush, 1997; Fredman et al, 2000; Thase et al, 2002; Rush and Ryan, 2002). The regulatory effects of switching from SSRIs to selective NRIs on serotonergic and noradrenergic parameters have not yet been explored preclinically (Thase and Rush, 1995; Fredman et al, 2000;

*Correspondence: Dr G Gould, Department of Pharmacology, UTHSCSA, MC 7764, 7703 Floyd Curl Drive, San Antonio, TX 78229-3900, USA, Tel: + I 210567 4205, Fax: + I 210567 4300, Email: gouldg@uthscsa.edu

Received 08 January 2003; revised 16 April 2003; accepted 02 May 2003

Online publication: 07 May 2003 at http://www.acnp.org/citations/ Npp050700 I/default.pdf
Rush and Ryan, 2002). It would be useful to know, for instance, if the effects of the second drug were enhanced, accelerated or diminished by prior treatment with the first drug. We therefore examined the effects of switching from the SSRI, paroxetine (PRX), to the selective NRI, reboxetine (RBX), on serotonergic and noradrenergic parameters that have been shown previously to be altered by treatment with either of these drug classes alone.

Regulatory changes observed in rat brain after 2-3 weeks of SSRI treatment include a decrease in serotonin transporter (SERT)-binding sites (Benmansour et al, 1999, 2002). Similar regulatory changes have been observed for the norepinephrine transporter (NET) after chronic treatment with the selective NRI, desipramine (Frazer and Benmansour, 2002), but have not yet been examined with RBX. In vitro, RBX is about 120 -fold more potent at blocking norepinephrine (NE) reuptake than serotonin (5-HT) reuptake (Wong et al, 2000). After either acute or chronic treatment, RBX increases extracellular NE levels in rat brain (Sacchetti et al, 1999; Invernizzi et al, 2001), while producing no effect on extracellular 5-HT (Millan et al, 2001). Considering the specificity of RBX for the noradrenergic system, we examined its long-term regulatory effects on the NET and noradrenergic receptors. We predicted that 
chronic RBX treatment, like desipramine, would decrease NET-binding sites in the rat brain. Also, radioligand binding to $\beta_{1}$ adrenergic receptors is decreased after chronic treatment of rats with NRIs (Ordway et al, 1988, 1991; Nelson et al, 1991). We therefore anticipated that chronic RBX treatment would similarly result in a decrease in $\beta_{1}$ adrenergic receptor binding. Further, a compensative regulatory effect observed in the locus coruleus after chronic treatment with AD drugs affecting the noradrenergic system such as desipramine, nortriptyline, and imipramine is a decrease in tyrosine hydroxylase (TH) gene expression levels (Nestler et al, 1990; Brady et al, 1991; Morilak et al, 1998). We predicted that chronic RBX treatment might also result in reduced mRNA expression for TH. Overall, we anticipate that selective NRIs, such as $\mathrm{RBX}$, will have regulatory effects on the noradrenergic system that parallel the effects that SSRIs, like PRX or sertraline, have on the serotonergic system. Thus, we measured the effects of treating rats with PRX or RBX, either alone or sequentially, on radioligand-binding sites for the SERT, NET, and $\beta_{1}$ adrenoceptors.

It was also of interest to determine if parameters not observed to change after monotherapy with noradrenergic reuptake inhibitors would be altered following sequential treatment. Radioligand binding to $\alpha_{2}$ adrenergic receptors in terminal fields appears to be unaltered by treatment with NE reuptake inhibitors (Kovachich et al, 1993; JimenezRivera et al, 1996). Also, while $\alpha_{1}$ adrenergic responsivity can be affected by chronic AD treatment (Rogoz and Kolasiewicz, 2001), radioligand binding to $\alpha_{1}$ adrenergic receptors has not been reported to be altered by such treatments. Consequently, we measured radioligand binding to sites for $\alpha_{1}$ and $\alpha_{2}$ adrenergic receptors in terminal fields.

\section{MATERIALS AND METHODS}

\section{Animals and Chronic Drug Treatments}

All animal procedures were reviewed and approved by the Institutional Animal Care and Use Committee of the University of Texas Health Science Center at San Antonio in accordance with NIH guidelines, and efforts were made to minimize animal use and suffering during the experiment. Male Sprague-Dawley rats (Harlan, Indianapolis, IN), weighing 175-200 g, were housed three per cage with ad libitum access to rat chow and water in a temperature- and humidity-controlled environment, with a $12 \mathrm{~h}$ light/dark cycle (lights on at $07.00 \mathrm{~h}$ ) for 1 week prior to surgery. At 1 day prior to surgery, osmotic minipumps delivering $2.5 \mu \mathrm{l} / \mathrm{h}$ (Model 2ML4, Alza Corporation, Palo Alto, CA) were filled with drug or vehicle (see Table 1 ), filtered through $0.8-\mu \mathrm{m}$ nitrocellulose filters (Millipore, Bedford, MA) using a sterile technique under an air-filtered hood. Drug solution concentrations were determined based on a mean rat weight of $280 \mathrm{~g}$ for the first 21 days of treatment. Minipumps were then stored in sealed containers filled with sterile saline in a $30-32^{\circ} \mathrm{C}$ incubator to prime the pumps until the time of surgery.

At the time of surgery, the rats (weighing 200-250 g) were anesthetized with an intramuscular injection of a cocktail of $34 \mathrm{mg} / \mathrm{kg}$ ketamine, $1 \mathrm{mg} / \mathrm{kg}$ acepromazine, and $7 \mathrm{mg} / \mathrm{kg}$ xylazine in saline. A drug-filled minipump was implanted
Table I 6-Week Drug Treatment Groups, Doses, and Sample Sizes

\begin{tabular}{rll}
\hline N & \multicolumn{1}{c}{$\begin{array}{c}\text { Drug treatment for } \\
\text { weeks I, 2, and 3 }\end{array}$} & \multicolumn{1}{c}{$\begin{array}{c}\text { Drug treatment for } \\
\text { weeks 4, 5, and 6 }\end{array}$} \\
\hline 26 & Vehicle control (saline or $50 \%$ & Vehicle control (Saline or $50 \%$ \\
& EtOH) $)^{\mathrm{a}}$ & EtOH) \\
7 & Paroxetine $(5 \mathrm{mg} / \mathrm{kg} / \mathrm{day})$ & Saline \\
9 & Paroxetine $(5 \mathrm{mg} / \mathrm{kg} / \mathrm{day})$ & Paroxetine $(5 \mathrm{mg} / \mathrm{kg} /$ day $)$ \\
11 & Paroxetine $(5 \mathrm{mg} / \mathrm{kg} / \mathrm{day})$ & Reboxetine $(20 \mathrm{mg} / \mathrm{kg} /$ day $)$ \\
8 & Saline & Reboxetine $(20 \mathrm{mg} / \mathrm{kg} /$ day $)$ \\
13 & Reboxetine $(20 \mathrm{mg} / \mathrm{kg} /$ day $)$ & Reboxetine $(20 \mathrm{mg} / \mathrm{kg} /$ day $)$ \\
\hline
\end{tabular}

a Saline is the vehicle control for reboxetine, whereas $50 \% \mathrm{EtOH}$ is the vehicle control for paroxetine. On all parameters measured, values obtained in the two control groups were not significantly different, so values are presented for the combined control groups.

subcutaneously on the rat's dorsum, approximately $3 \mathrm{~cm}$ below the neck, and the rat was injected with penicillin. After 21 days of drug treatment, the minipumps were removed, and a new minipump with a second 3-week treatment of drug or vehicle was implanted. The approximate weight of rats at the time of surgery for the second treatment was $320 \mathrm{~g}$, so drug concentrations were based on an estimated body weight of $380 \mathrm{~g}$ for the second 21-day treatment. Table 1 summarizes pretreatments, treatments, and sample sizes for each experimental group.

Selection of the dose of RBX was determined from a pilot study that aimed to determine steady-state serum levels after 6-12 days of drug administration via minipump. Six concentrations of RBX were tested to determine the dose needed to obtain a steady-state serum concentration within the therapeutic range observed in humans. RBX doses of 30 , $20,10,5$, and $2.5 \mathrm{mg} / \mathrm{kg} /$ day produced serum values of $1196 \pm 122,191 \pm 38,86 \pm 18,40 \pm 7$, and $20 \pm 2 \mathrm{ng} / \mathrm{ml}$, respectively. The RBX concentration used in this study was $20 \mathrm{mg} / \mathrm{kg} / \mathrm{day}$, which produced a serum concentration close to human therapeutic values (Fleishaker et al, 1999). As the affinity of RBX for the rat and human NET is comparable (Wong et al, 2000), attaining 'therapeutic' serum concentrations is relevant for a study in rats. Selection of the dose of PRX was based on a similar rationale and results from a previous study (Benmansour et al, 1999). Washout times needed after drug treatments to establish serum levels of drug $<5 \mathrm{ng} / \mathrm{ml}$ were also obtained from Benmansour et al (1999) for PRX (96h) and were determined experimentally for $\mathrm{RBX}(48 \mathrm{~h})$. Saline was the vehicle control for RBX, whereas 50\% ethanol was the vehicle control for PRX. On all parameters measured, values obtained in the two control groups were not significantly different, so values are presented for the combined control groups.

Upon completion of the drug treatments, the minipumps were removed. After the appropriate washout times, rats were euthanized by decapitation and their brains were removed, rinsed in ice-cold saline, frozen quickly on dry ice, and stored at $-80^{\circ} \mathrm{C}$ until use.

\section{Brain Tissue Preparation}

Coronal sections $(20 \mu \mathrm{m})$ of frozen rat brain were cut on a $16^{\circ} \mathrm{C}$ cryostat (Leica Frigocut, $2800 \mathrm{~N}$, Deerfield, IL) at the level of plate 18-20 for the bed nucleus of the striata 
terminalis, plate 28-33 for amygdala and hippocampus, plate 47-50 for dorsal raphe, and plate 56-59 for locus coeruleus, according to the stereotaxic atlas of Paxinos and Watson (1986). Sections for quantitative autoradiography were thaw-mounted onto gelatin or silane-coated, chilled microscope slides and dried under vacuum for $12 \mathrm{~h}$ at $4{ }^{\circ} \mathrm{C}$. Sections for in situ hybridization were thaw-mounted onto silane-coated, chilled microscope slides, fixed in $4 \%$ paraformaldehyde, washed in phosphate-buffered saline, dehydrated in ethanol, and air-dried. Sections on slides were stored at $-80^{\circ} \mathrm{C}$ until use in assays.

\section{Quantitative Autoradiography}

The densities of NET, $\alpha_{1}, \alpha_{2}$, and $\beta_{1}$ noradrenergic receptorbinding sites, as well as those for the SERT were examined by quantitative autoradiography. Table 2 summarizes these procedures and the materials used. Preliminary experiments showed equivalent binding of either $\left[{ }^{3} \mathrm{H}\right]$ cyanoimipramine or $\left[{ }^{3} \mathrm{H}\right]$ nisoxetine in brain slices of chronic drug-treated rats if there was no preincubation or preincubations up to $60 \mathrm{~min}$. For the NET and SERT incubation solutions, radioligand concentrations were 5-9 times the ligand's $K_{\mathrm{D}}$ value, so as to obtain binding site densities approximating $B_{\max }$ values. Incubation solutions of the iodinated ligands were at the ligand's $K_{\mathrm{D}}$ value and therefore, binding site densities represent nonmaximal values. Large incubation volumes $(10 \mathrm{ml})$ were used for all incubations that would produce dilution of any residual drug coming out of the brain slices. Following incubation, the sections on slides were washed in ice-cold buffer, dipped for $1 \mathrm{~s}$ in ice-cold distilled-deionized water to remove buffer salts, and dried on a slide warmer (Labline, Fisher Scientific, USA).

All quantitative autoradiography sections on slides were exposed to Hyperfilm- ${ }^{3} \mathrm{H}$ (CEA AB Sweden for Amersham) along with tritium standards (American Radiolabeled Chemicals, St Louis, MO) calibrated against brain mash for $\left[{ }^{3} \mathrm{H}\right]$ as per Geary et al $(1985)$ or $\left[{ }^{125} \mathrm{I}\right]$ as per Artymyshyn et al (1990). Films were developed using Kodak GBX developer, stop bath, and fixer. Autoradiograms were analyzed using NIH image-based Scion Image $1.60 \mathrm{c}$ (public domain shareware http://scioncorp.com) on a Macintosh IICi computer. Optical densities of brain images were converted to femtomoles per milligram as per Geary et al (1985) or Artymyshyn et al (1990).

MANOVA tests were used to analyze the effects of the chronic drug treatments on all brain regions quantified using Statistica for the Macintosh (Statsoft, Tulsa, OK). Significant multivariate results were examined post hoc by ANOVA followed by Neuman-Keuls post hoc test.

\section{In Situ Hybridization with TH Riboprobes}

In situ hybridization was conducted as described previously (Sands et al, 2000a). The $275 \mathrm{nt}$ TH probe was transcribed from cDNA templates provided by Dr Stanley Watson (University of Michigan), with addition of $\alpha-{ }^{35}$ S-UTP (New England Nuclear) to a specific activity of $2 \times 10^{9} \mathrm{cpm} / \mu \mathrm{g}$. All prehybridization and hybridization solutions were treated with diethyl pyrocarbonate. Brains sections were hydrated, acetylated, rinsed in $2 \times$ sodium chloride-sodium citrate buffer (SSC), dehydrated in ethanol, delipidated in chloro-

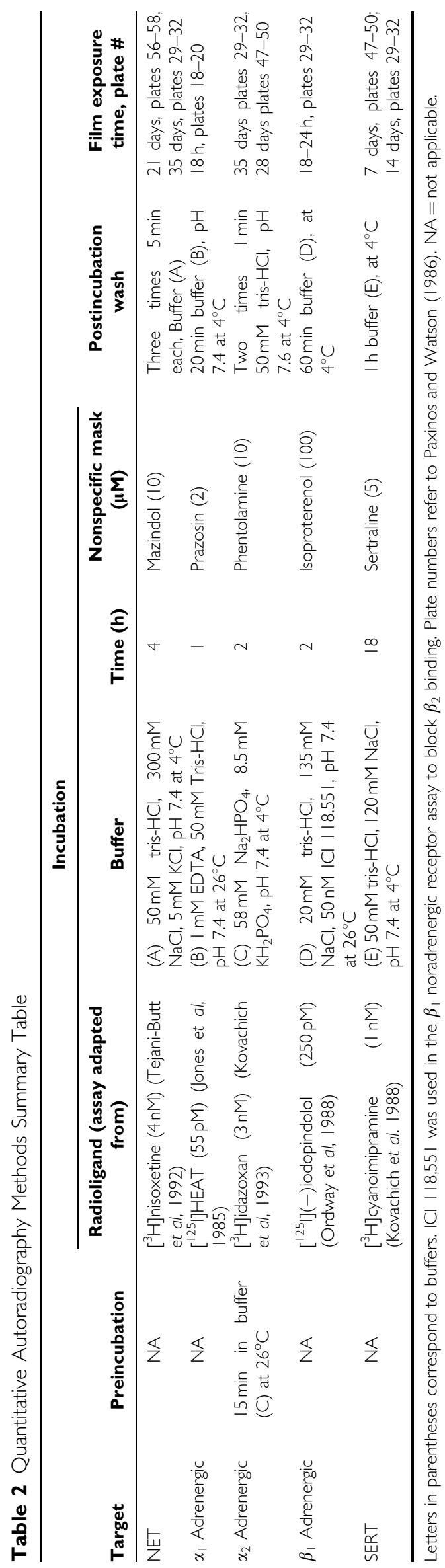


form, and air-dried. Sections were hybridized overnight at $60^{\circ} \mathrm{C}$ under glass coverslips in $50 \mu$ l hybridization buffer containing $4 \times 10^{7} \mathrm{cpm} / \mathrm{ml}$ radiolabeled riboprobe (approximately $20 \mathrm{ng} / \mathrm{ml}$ ). All posthybridization solutions contained $1 \mathrm{mM}$ dithiothreitol. After hybridization, sections were rinsed, and excess probe was removed by digestion with RNAse A $\left(20 \mu \mathrm{g} / \mathrm{ml}, 30 \mathrm{~min}\right.$ at $\left.37^{\circ} \mathrm{C}\right)$, followed by a series of washes of increasing stringency: $10 \mathrm{~min}$ each in $1 \times \mathrm{SSC}$, $0.5 \times$ SSC, $0.2 \times$ SSC. Sections were washed for $10 \mathrm{~min}$ in $0.1 \times$ SSC and $3 \times 1 \mathrm{~h}$ in $0.1 \times \mathrm{SSC}, 15 \%$ formamide, at $60^{\circ} \mathrm{C}$. Sections were then rinsed, dehydrated, and apposed to Kodak Biomax MR X-ray film along with a set of ${ }^{14} \mathrm{C}$ radioactive standards for $16 \mathrm{~h}$.

After developing the films, signals overlying the LC on digitized autoradiographic images were analyzed densitometrically using NIH-Image (v. 1.55, Wayne Rasband, NIH). Integrated density was calibrated in units of $\mathrm{nCi} / \mathrm{mg}$ using the ${ }^{14} \mathrm{C}$-standards, and measured in 4-6 LC sections per brain, corresponding to plates 56-58 in the atlas of Paxinos and Watson (1986). The mean integrated density was then calculated to generate a single value for each animal. Data obtained from brains in different hybridizations were combined into groups by expressing all individual values as a percentage of the mean baseline value for the 6-week PBS-treated control rats analyzed within the same hybridization. Resulting group data were compared using one-way ANOVA, followed by post hoc comparisons with Fisher's PLSD test. Significance was determined at $P<0.05$.

\section{Liquid Chromatography Analysis of Serum Drug Levels}

Serum concentrations of PRX were determined by highperformance liquid chromatography (HPLC) as described in Benmansour et al (1999). Serum RBX concentrations were determined by HPLC as described in Fleishaker et al (1999).

\section{Drugs}

RBX was obtained from Pharmacia (Kalamazoo, MI). PRX was obtained from SmithKline Beecham (Harlow, England).
Prazosin, phentolamine, and isoproterenol were obtained from Sigma (St Louis, MO). Mazindol was obtained from Sandoz (East Hanover, NJ). Sertraline was obtained from Pfiser (Groton, CT). ICI 118,551 was obtained from Imperial Chemical Industries (Cheshire, England). $\left[{ }^{3} \mathrm{H}\right]$ nisoxetine $(80-85 \mathrm{Ci} / \mathrm{mmol})$ and $\left[{ }^{3} \mathrm{H}\right]$ idazoxan $(82 \mathrm{Ci} / \mathrm{mmol})$ were obtained from Amersham (Arlington Heights, IL). $\left[{ }^{3} \mathrm{H}\right]$ cyanoimipramine $(80-85 \mathrm{Ci} / \mathrm{mmol})$ was obtained from American Radiolabeled Chemicals (St Louis, MO). $\left[{ }^{125} \mathrm{I}\right] \mathrm{HEAT}$ and $\left[{ }^{125} \mathrm{I}\right](-)$ iodopindolol, both $2200 \mathrm{Ci} / \mathrm{mmol}$, were obtained from Perkin-Elmer-NEN (Boston, MA).

\section{RESULTS}

\section{Quantitative Autoradiography of Noradrenergic Parameters}

Treatment with RBX produced qualitatively similar reductions in the binding of $\left[{ }^{3} \mathrm{H}\right]$ nisoxetine in the noradrenergic terminal fields measured. For illustrative purposes, results found in the arcuate nucleus of the hypothalamus (ARC), the dentate gyrus (DG) of the hippocampus, and the lateral nucleus of the amygdala (LA) are shown in Figure 1. Also measured, but not shown, were results in the CA1 region of the hippocampus and the frontal parietal cortex. The decrease in NET binding after 3 weeks of treatment with RBX was significant in the ARC, LA, and CA1 $(P<0.01)$, but not in the DG and cortex. Treatment with RBX for 6 weeks decreased NET-binding sites significantly in all areas measured $(P<0.001)$. In rats treated with RBX for 3 weeks, there were significantly smaller effects on $\left[{ }^{3} \mathrm{H}\right]$ nisoxetine binding (about $40-45 \%$ reductions) than that seen after 6 weeks of treatment $(50-60 \%$ reductions) in four of five brain regions measured $(P<0.025)$, but not in the LA. Neither PRX treatment for 6 weeks, nor 3 weeks of PRX treatment followed by 3 weeks of saline had any significant effect on NET-binding sites (Figure 1).

Interestingly, a 3-week treatment with PRX followed by a 3-week treatment with RBX produced decreases in $\left[{ }^{3} \mathrm{H}\right]$ nisoxetine binding significantly greater than that caused by 3
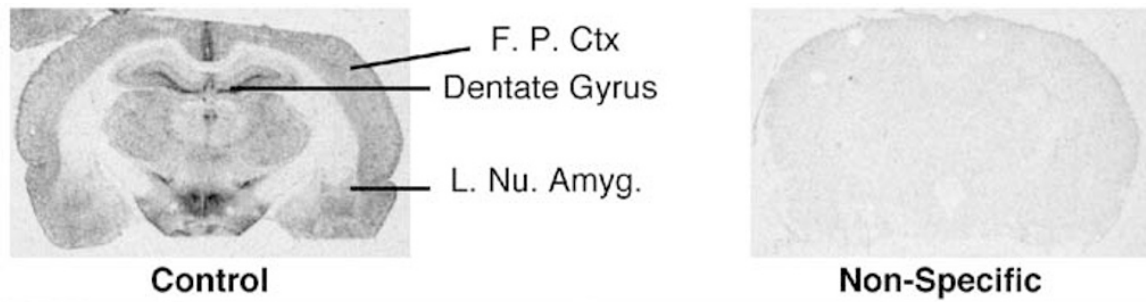

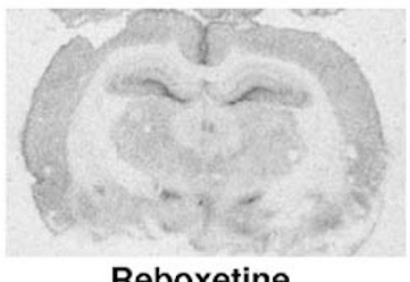

Reboxetine

(3 wk)

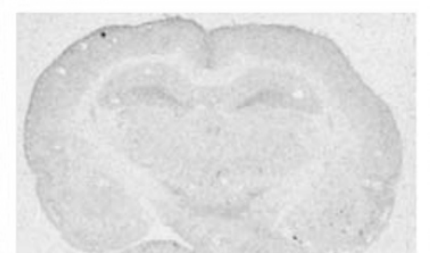

Reboxetine

$(6 \mathrm{wk})$

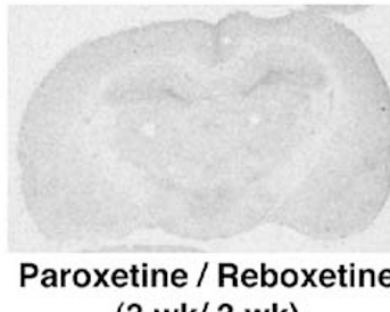

$(3 \mathrm{wk} / 3 \mathrm{wk})$

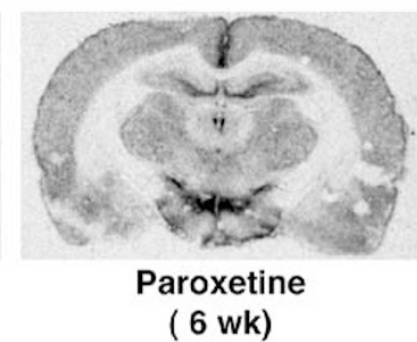

Figure I Representative autoradiograms for $\left[{ }^{3} \mathrm{H}\right]$ nisoxetine binding in terminal field areas. Typical autoradiograms for either saline or $50 \%$ ethanol vehicle controls, 3 and 6 weeks of RBX treatment, 6 weeks of PRX treatment, 3 weeks of PRX treatment followed by 3 weeks of RBX treatment, and nonspecific binding, defined by $10 \mu \mathrm{m}$ mazindol are shown. FPCtx = frontal parietal cortex, L. Nu. Amyg=lateral nucleus of the amygdala. 
weeks of RBX alone in four of five brain regions measured $(P<0.05$, see Figure 1$)$, the exception being in the LA. The effect of this sequential treatment was similar to 6 weeks of RBX treatment, with a decrease in NET binding of $60-70 \%$ in the terminal field areas.

The effects of the various treatments on $\beta 1$ adrenergic receptor-binding sites in the basolateral nucleus of the amygdala (BLA) and the CA1 region of the hippocampus are shown in Figure 2. The LA and layers 1-3 of the frontal parietal cortex were also measured, but are not shown in Figure 2. Results in these areas were similar to those found in the BLA and CA1 region. RBX produced significant decreases of a similar magnitude, on the order of $40-60 \%$,

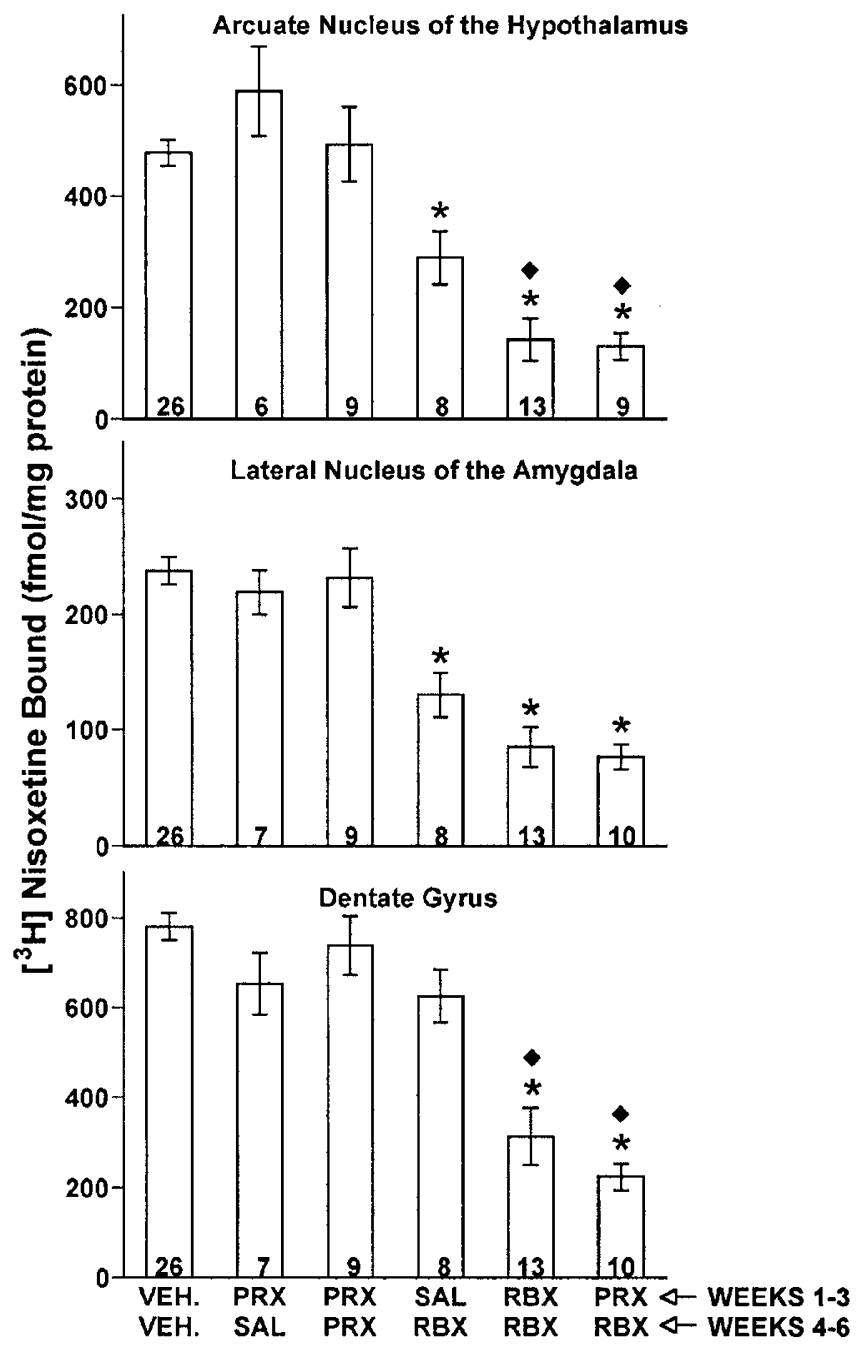

Figure 2 NET density in representative brain regions. Bars indicate means + standard errors; sample size $(N)$ is indicated within each bar $\mathrm{VEH} .=$ vehicle control (50\% EtOH or saline), $\mathrm{PRX}=$ paroxetine, $\mathrm{SAL}=$ sasaline, $\mathrm{RBX}=$ reboxetine. All brain regions measured had significant differences between treatment groups $(P<0.001)$. Results in the arcuate nucleus of the hypothalamus $\left(\mathrm{F}_{5,65}=22\right)$, dentate gyrus $\left(F_{5,67}=25\right)$, and the lateral nucleus of the amygdala $\left(F_{5,67}=23\right)$ are shown in this figure. Drug treatment groups indicated with an $*$ exhibited $\left[{ }^{3} \mathrm{H}\right]$ nisoxetine binding that was significantly less than that in the vehicle control $(P<0.001$, Neuman-Keul's). RBX treatment groups indicated with a exhibited $\left[{ }^{3} \mathrm{H}\right]$ nisoxetine binding that was significantly less than that in the corresponding 3-week RBX treatment $(P<0.05$, Neuman-Keul's). in the binding of $\left[{ }^{125} \mathrm{I}\right]$ iodopindolol to $\beta_{1}$ adrenergic receptors in all terminal fields, both at 3 and 6 weeks of treatment $(P<0.001$, Figure 2$)$. The sequential treatment of PRX followed by RBX produced decreases in $\left[{ }^{125} \mathrm{I}\right]$ iodopindolol binding not significantly different from that caused by 3 weeks of RBX treatment alone. Treatment with PRX for 6 weeks or treatment with the SSRI for 3 weeks followed by 3 weeks of saline did not significantly alter the binding of $\left[{ }^{125} \mathrm{I}\right]$ iodopindolol (Figure 2).

In the terminal fields, none of the drug treatments produced any significant changes in radioligand binding to either $\alpha_{1}$ or $\alpha_{2}$ adrenergic receptors (see Table 3).

\section{Quantitative Autoradiography of the SERT}

For illustrative purposes, the treatment-induced effects on $\left[{ }^{3} \mathrm{H}\right]$ cyanoimipramine binding to the SERT in two terminal field areas and one cell body area are shown in Figure 3. Chronic RBX treatment did not produce any significant decreases in $\left[{ }^{3} \mathrm{H}\right]$ cyanoimipramine binding in any region of the brain. By contrast, treatment with PRX for 6 weeks produced a $50-80 \%$ decrease $(P<0.001)$ in binding in both serotonergic terminal areas and cell bodies, consistent with our previous data after 3 weeks of treatment (Benmansour et al, 1999). Rats treated with PRX for 3 weeks followed by either 3 weeks of saline or 3 weeks of RBX exhibited no significant decrease in $\left[{ }^{3} \mathrm{H}\right]$ cyanoimipramine binding. Also measured, but not shown, were the CAl region of the hippocampus, arcuate nucleus of the hypothalamus, frontal parietal cortex, and the medial raphe nucleus. Results in these areas were very similar to those found in the areas shown (Figure 4).

\section{In Situ Hybridization for TH}

No significant main effect of treatment condition was observed on the level of mRNA expression for TH in the LC $\left(\mathrm{F}_{6,65}=0.96, P=0.46\right.$; Table 3).

\section{DISCUSSION}

The primary observation in this study was that pretreatment with PRX enhanced the timing and magnitude of at least one regulatory effect of RBX treatment, namely downregulation of the NET. When 3 weeks of RBX treatment followed 3 weeks of prior treatment with the SSRI PRX, the resulting decrease in NET binding was similar to that seen after 6 weeks of RBX treatment (Figure 2). By contrast, on the other parameters measured, the effects of RBX were qualitatively similar, whether given alone or following pretreatment with PRX. There was no enhancement of RBX's inhibitory effects on $\beta_{1}$ adrenergic receptor-binding site density, and there was no residual effect of the PRX pretreatment on the SERT-binding density in rats subsequently treated with RBX. However, it seems likely that 3 weeks of RBX treatment was sufficient to induce maximal decreases in $\beta_{1}$ adrenergic receptor sites, thus any potential facilitation by PRX may not have been evident. This is suggested by the observation that 3 weeks of RBX decreased $\beta_{1}$ adrenergic receptor binding to an equivalent extent as that caused by desipramine treatment in a previous study (Ordway et al, 1991) and to a extent 
Table 3 Binding to $\alpha$ Adrenergic Receptors (fmol/mg Protein) in Representative Brain Regions, and Expression of mRNA for Tyrosine Hydroxylase in the Locus Coruleus (\% of Normalized Control)

\begin{tabular}{|c|c|c|c|c|c|c|}
\hline Treatment weeks I-3/weeks 4-6 & $\mathbf{N}$ & $\begin{array}{c}\alpha_{1} \text { Adrenergic } \\
{\left[{ }^{125} I\right] \text { HEAT }} \\
\text { Bed n. stria ter. }\end{array}$ & $\mathbf{N}$ & $\begin{array}{c}\alpha_{2} \text { Adrenergic } \\
{\left[{ }^{3} \mathrm{H}\right] \text { idazoxan }} \\
\text { Basomedial nu. amyg. }\end{array}$ & $\mathbf{N}$ & $\begin{array}{c}\text { Tyrosine hydroxylase } \\
\text { mRNA } \\
\text { Locus coruleus }\end{array}$ \\
\hline Vehicle control & 12 & $89.8 \pm 1.4^{\mathrm{a}}$ & 15 & $1360.0 \pm 63.0$ & 27 & $102.0 \pm 5.2^{b}$ \\
\hline Paroxetine/paroxetine & 5 & $94.1 \pm 2.0$ & 9 & $1370.1 \pm 49.4$ & 7 & $81.3 \pm 8.5$ \\
\hline Saline/reboxetine & 6 & $85.5 \pm 1.4$ & 6 & $1447.8 \pm 1 \mid 5.6$ & 8 & $98.7 \pm 6.3$ \\
\hline Reboxetine/reboxetine & 13 & $87.2 \pm 1.6$ & 13 & $1214.6 \pm 81.0$ & 12 & $97.6 \pm 8.5$ \\
\hline
\end{tabular}

aMean \pm standard error.

b\% Mean \pm standard error baseline density values for all saline control brains quantified within the same hybridization.

No significant differences were found between drug treatments for $\alpha$ adrenergic receptor binding sites in the terminal fields. For illustrative purposes, $\left.{ }^{125}{ }_{1}\right] \mathrm{HEAT}$ binding to $\alpha_{1}$ adrenergic receptors in the bed nucleus of the stria terminalis and $\left[{ }^{3} \mathrm{H}\right]$ idazoxan binding to $\alpha_{2}$ adrenergic receptors in the basomedial amygdaloid nucleus are shown, as these areas have relatively high densities of their respective receptors (NA $=$ not analyzed).

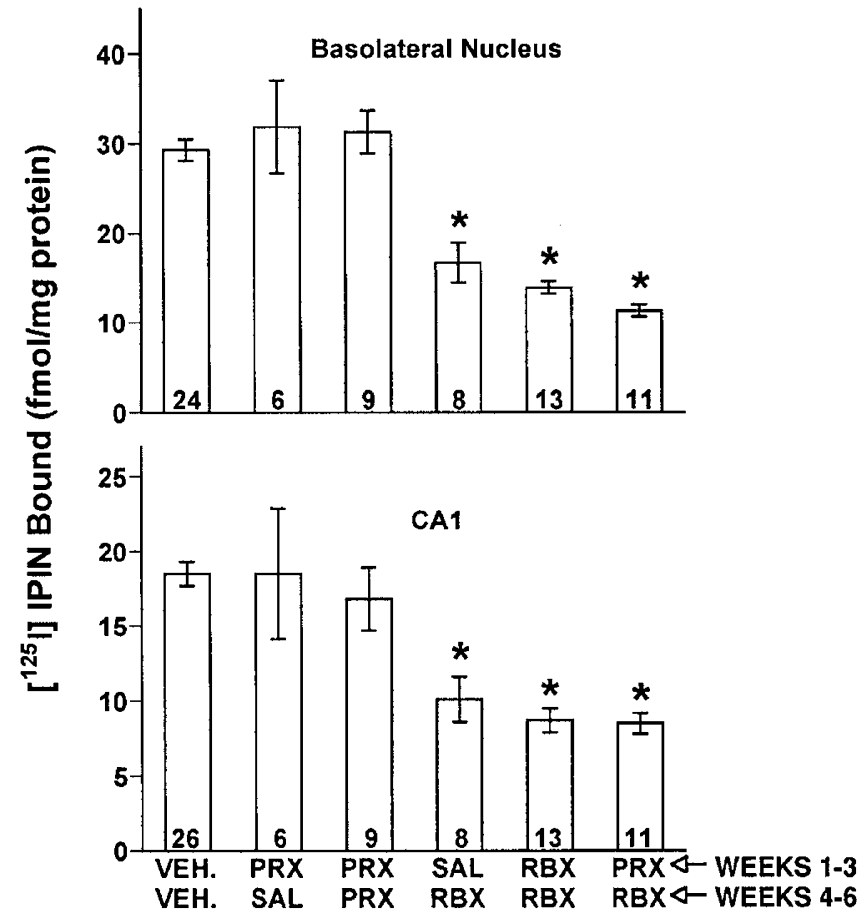

Figure $3 \beta_{\text {। }}$ adrenergic receptor binding in the basolateral nucleus of the amygdala and CAI region of the hippocampus. See Figure I for abbreviations. All brain regions measured had significant differences between treatment groups $(P<0.00 \mathrm{I})$. The $\mathrm{CAl}$ region of the hippocampus $\left(F_{5,67}=14\right)$ and the basolateral nucleus of the amygdala $\left(F_{5,65}=30\right)$ are shown in this figure. Drug treatment groups indicated with an * exhibited [ ${ }^{125}$ ] iodopindolol binding that was significantly less than that in the vehicle control $(P<0.00$ I, Neuman-Keul's).

similar to that caused by 6 weeks of RBX treatment (Figure 2).

By contrast with the 'priming' of RBX's regulatory effects on the NET that was precipitated by PRX pretreatment, the reverse effect was not observed, that is, we did not observe any 'conversion of effect' of RBX treatment. That is, RBX treatment did not sustain any regulatory effects that the initial PRX treatment may have exerted on SERT radioligand-binding sites. We know from previous studies that after cessation of treatment with the SSRI sertraline, SERT densities recover to pretreatment levels within 2 weeks (Benmansour et al, 2002). Evidently, RBX treatment neither prolonged or sustained the paroxetine-induced downregulation of the SERT, nor did it interfere with the recovery of SERT density in the timeframe of our observations.

PRX is a potent inhibitor of 5-HT reuptake, but it also inhibits NE reuptake with a greater potency than that of other SSRIs (Frazer, 2001). PRX exhibits a moderate affinity for the NET (Owens et al, 1997), and has been shown to have modest effects on the NET at serum concentrations $>100 \mathrm{ng} / \mathrm{ml}$ (Owens et al, 2000; Gilmor et al, 2002). Nonetheless, PRX treatment alone for 6 weeks did not affect any of the noradrenergic parameters measured in this study. PRX had no effect on NET or $\beta_{1}$ adrenergic receptorbinding sites, whereas drugs that block NE reuptake, that is, desipramine (Frazer and Benmansour, 2002) and RBX (Figures 1 and 2), did. Thus, this dose of PRX, which produces serum concentrations of the drug in the 'therapeutic' range (Benmansour et al, 1999), is unlikely to have exhibited any direct long-term regulatory effects on the NE system.

Similar to the tricyclic antidepressant desipramine, RBX has been shown to selectively increase extracellular NE in the cortex, hippocampus, and other brain regions, presumably through reuptake blockade, without affecting serotonin levels (Sacchetti et al, 1999; Invernizzi et al, 2001; Page and Lucki, 2002). Based on these studies, we anticipated that RBX would not affect the SERT, and it did not. Reduction of NET binding following 3 and 6 weeks of chronic treatment with $\mathrm{RBX}$ was similar to the downregulation of NET observed following chronic desipramine treatment (Frazer and Benmansour, 2002). The selective downregulatory effects on the NET observed after chronic $\mathrm{RBX}$ treatment are therefore consistent with its function as a selective NRI.

Other interactive effects of treatment with an SSRI and a selective NRI have been observed. For example, subacute simultaneous treatment of RBX and sertraline made recovery from both 8-OH-DPAT and clonidine-induced responses more rapidly than the time course of recovery with either treatment alone, suggesting that the two drugs together accelerated changes to the responsiveness of 5- 


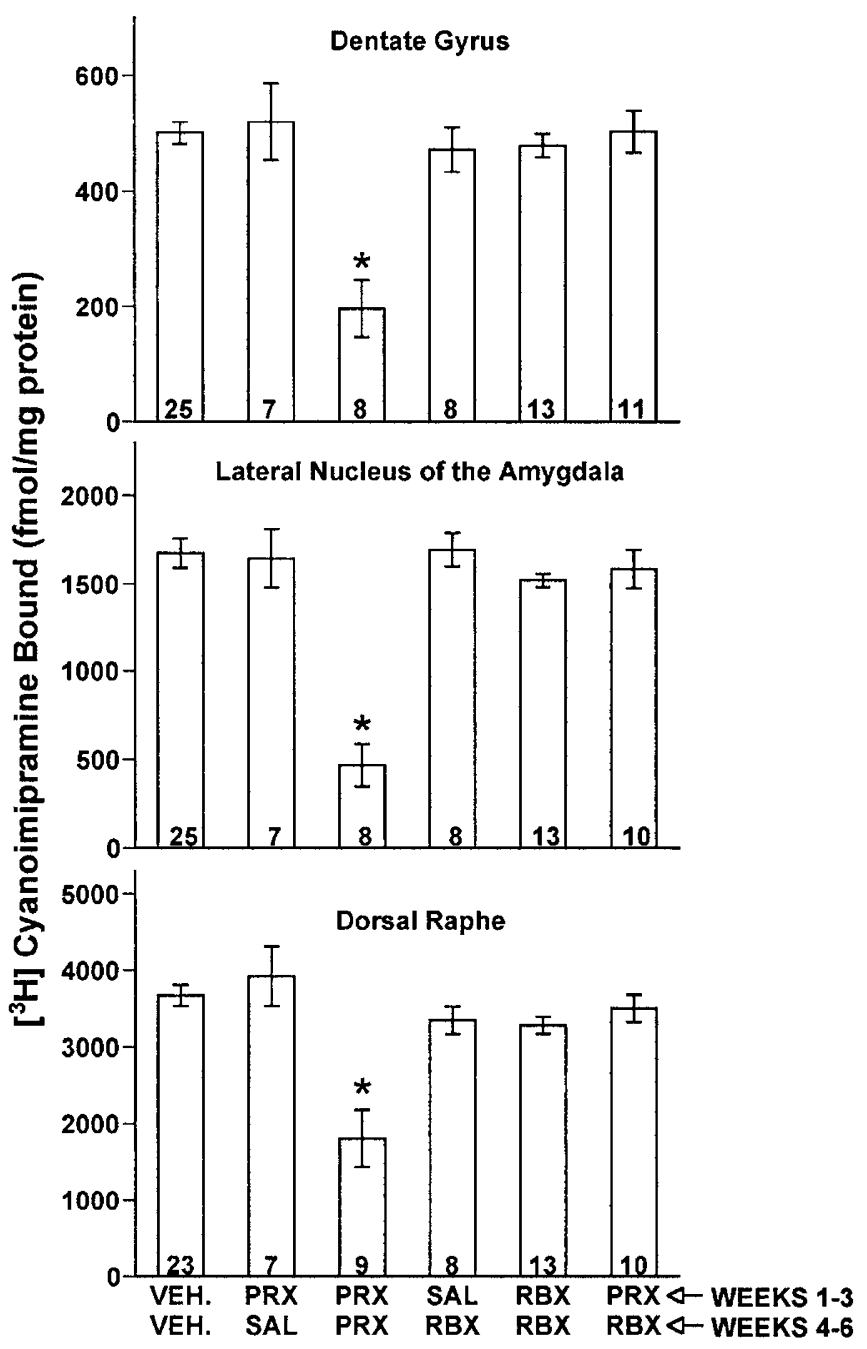

Figure 4 SERT density in representative brain regions. See Figure I for abbreviations. All brain regions measured had significant differences between treatment groups $(P<0.00 \mathrm{I})$, and included the dentate gyrus $\left(F_{5,66}=11\right)$, lateral nucleus of the amygdala $\left(F_{5,66}=17\right)$, and the dorsal raphe nucleus $\left(F_{5,64}=12\right)$, shown in the figure. Only 6 weeks of PRX treatment produced a significant reduction in $\left[{ }^{3} \mathrm{H}\right]$ cyanoimipramine binding, which was significant in all regions measured $(P<0.005$, Newman-Keul's). Drug treatment groups indicated with an * exhibited $\left[{ }^{3} \mathrm{H}\right]$ cyanoimipramine binding that was significantly less than that in the vehicle control $(P<0.00$ I, Neuman-Keul's).

$\mathrm{HT}_{1 \mathrm{~A}}$ and $\alpha_{2}$-adrenoceptors (Harkin et al, 1999). Chronic coadministration of desipramine and fluoxetine caused desipramine-mediated downregulation of $\beta$ adrenergic receptors to occur more rapidly (Baron et al, 1988). In microdialysis studies, a $120 \mathrm{~min}$ acute pretreatment with fluoxetine potentiated the effects of acute administration of bupropion (a dual NE and dopamine (DA) reuptake inhibitor) to increase extracellular NE and DA concentrations in the hypothalamus, cortex, and nucleus accumbens (Li et al, 2002).

We did not observe any decrease in mRNA expression for TH after chronic SSRI or selective NRI treatment (Table 3). Findings of changes in gene expression for $\mathrm{TH}$ with chronic antidepressant treatment are variable. Nestler et al (1990) found that after 2 weeks of chronic treatment, all major classes of antidepressant treatment decreased the expres- sion of mRNA for TH in the locus coruleus. By contrast, Brady et al (1991) found that either 2 or 8 weeks of administration of fluoxetine, idazoxan, and phenelzine produced an increase in the expression of mRNA for the TH in the locus coruleus. Brady et al (1991) also found that 8 weeks of imipramine treatment decreased TH mRNA expression by $40 \%$. Chronic administration of desipramine for 6 weeks was shown to decrease TH mRNA in the LC (Morilak et al, 1998), but chronic RBX did not do the same in our current study. Perhaps differences in the mode of drug administration could have contributed to this difference. In previous studies, where mRNA expression for TH was increased, it may have been due to the stress of chronic daily injections. Both chronic stress and acute stress have been shown to increase mRNA expression for TH and TH activity in the locus coruleus (Brady, 1994; Sands et al, $2000 \mathrm{~b}$ ). Our use of osmotic minipumps may have reduced the stress associated with the injections, which may explain why neither RBX nor PRX increased mRNA levels. However, we did not observe a decrease either, as was found previously with desipramine (Morilak et al, 1998). Perhaps the reduction in mRNA expression for TH that was observed after desipramine treatment may have been triggered by its effects on other receptor types (ie $\mathrm{H}_{1}$ histaminergic, $\alpha_{1}$ adrenergic, muscarinic-cholinergic, or dopaminergic). If so, then RBX's lack of effect on such receptors (Wong et al, 2000) may account for its inability to elicit changes in TH gene expression. Likewise, the lack of effect of chronic RBX treatment on $\alpha_{1}$ adrenergic receptor binding (Table 3) was consistent with the findings of others (eg Rogoz and Kolasiewicz, 2001).

RBX had no effect on $\alpha_{2}$ adrenergic receptor density in the terminal fields, where both presynaptic autoreceptors and postsynaptic receptors coincide. The effect that NE-specific reuptake blockade may have on $\alpha_{2}$ adrenergic receptors of the cell body area of the locus coruleus remains unclear and warrants further investigation. Chronic imipramine treatment produced a modest decrease in the numbers of $\alpha_{2}$ receptors in the locus coruleus (Jimenez-Rivera et al, 1996). Thus, NE-specific antidepressant-induced decreases in the density of $\alpha_{2}$ receptors are more likely to be found in the cell bodies (Kovachich et al, 1993). However, consistent with the lack of effect of RBX on terminal $\alpha_{2}$ receptor density in the present study, chronic desipramine treatment failed to produce downregulation of $\alpha_{2}$ receptors in the locus coruleus (Sacchetti et al, 2001). Nevertheless, chronic RBX treatment has been shown through microdialysis studies to desensitize presynaptic $\alpha_{2}$ adrenoceptors (Invernizzi et al, 2001). Linner et al (1999) demonstrated that acute imipramine treatment profoundly inhibited the level of firing in LC neurons, and this effect was only slightly attenuated after chronic imipramine treatment. They observed a corresponding increase in cortical NE levels with chronic imipramine treatment, which they attributed to desensitization of presynaptic $\alpha_{2}$ autoreceptors (Linner et al, 1999). Our data suggest, however, that there may be an additional mechanism responsible for the observed increase in extracellular NE with chronic NRI treatment. In addition to continuous pharmacologic blockade of the transporter and possible desensitization of $\alpha_{2}$ adrenoceptors, downregulation of the NET may also be involved in elevated extracellular NE. Evidence in support of such an interpreta- 
tion has been obtained in investigations of the SERT in vivo. Decreased clearance of serotonin by the SERT was much more robust following downregulation of the SERT than that due to blockade of the SERT by SSRIs (Benmansour et al, 2002).

Overall, our findings suggest that switching from PRX to RBX may have 'primed' the noradrenergic system for downregulation of the NET by RBX through unknown 5$\mathrm{HT} / \mathrm{NE}$ system interactions. It is useful to know that switching from an SSRI to a selective NRI does not appear to impose any unforeseen challenges to perhaps important regulatory effects of the selective NRI. Thus, switching a nonresponding patient from an SSRI to a selective NRI such as RBX may be a viable strategy insofar as no regulatory effects of RBX on the noradrenergic system are compromised and there may even be temporal enhancement on some parameters.

While to date there have been few controlled, randomized clinical trials examining the effects of switching antidepressants in nonrespondent patients, a new initiative, Sequenced Treatment Alternatives to Relieve Depression, endeavors to do so for patients (Rush and Ryan, 2002). In turn, preclinical studies such as this one, examining the effects of sequential treatment with different classes of antidepressants on neurotransmitter regulation in the brain, can help to elucidate underlying mechanisms responsible for regulatory changes in 5-HT and/or NE neurotransmission.

\section{ACKNOWLEDGEMENTS}

This work was supported by Pharmacia \& Upjohn \& NIMH Grant MH57001. Expert technical assistance was provided by Elizabeth Blackman, Lauren Phillips, and April Garcia. Dr Saloua Benmansour shared her expertise on the techniques used, and provided editorial suggestions. HPLC analyses of serum drug levels were performed by Dr Martin Javors, Department of Psychiatry, UTHSCSA, San Antonio, Texas and Mike Allen, Triangle Laboratories, Inc. Durham, North Carolina.

\section{REFERENCES}

Artymyshyn R, Smith A, Wolfe BB (1990). The use of ${ }^{3} \mathrm{H}$ standards in ${ }^{125} \mathrm{I}$ autoradiography. Neurosci Methods 32: 185-192.

Baron BM, Ogden AM, Siegel BW, Stegeman J, Ursillo RC, Dudley MW (1988). Rapid down regulation of beta-adrenoceptors by coadministration of desipramine and fluoxetine. Eur J Pharmacol 154: 125-134.

Benmansour S, Cecchi M, Morilak DA, Gerhardt GA, Javors MA, Gould GG et al (1999). Effects of chronic antidepressant treatments on serotonin transporter function, density and mRNA level. J Neurosci 19: 10494-10501.

Benmansour S, Owens WA, Cecchi M, Morilak DA, Frazer A (2002). Serotonin clearance in vivo is altered to a greater extent by antidepressant-induced downregulation of the serotonin transporter than by acute blockade of this transporter. J Neurosci 22: 6766-6772.

Brady LS (1994). Stress, antidepressant drugs, and the locus coeruleus. Brain Res Bull 35: 545-556.

Brady LS, Whitfield Jr HJ, Fox RJ, Gold PW, Herkenham M (1991). Long-term antidepressant administration alters corticotropin-releasing hormone, tyrosine hydroxylase, and mineralo- corticoid receptor gene expression in rat brain. Therapeutic implications. J Clin Invest 87: 831-837.

Fava M (2000). New approaches to the treatment of refractory depression. J Clin Psychiatry 61(Suppl 1): 26-32.

Fleishaker JC, Herman BD, Pearson LK, Ionita A, Mucci M (1999). Evaluation of the potential pharmacokinetic/pharmacodynamic interaction between fluoxetine and reboxetine in healthy volunteers. Clin Drug Invest 18: 141-150.

Frazer A (2001). Serotonergic and noradrenergic reuptake inhibitors: prediction of clinical effects from in vitro potencies. $J$ Clin Psychiatry 62: 16-23.

Frazer A, Benmansour S (2002). Delayed pharmacological effects of antidepressants. Mol Psychiatry 7(Suppl 1): S23-S28.

Fredman SJ, Fava M, Kienke AS, White CN, Nierenberg AA, Rosenbaum JF (2000). Partial response, nonresponse, and relapse with selective serotonin reuptake inhibitors in major depression: a survey of current 'next-step' practices. J Clin Psychiatry 61: 403-408.

Gilmor ML, Owens MJ, Nemeroff CB (2002). Inhibition of norepinephrine uptake in patients with major depression treated with paroxetine. Am J Psychiatry 159: 1702-1710.

Geary WA, Tioga AW, Wooten GF (1985). Quantitative film autoradiography for tritium: methodological considerations. Brain Res 337: 99-108.

Harkin A, Kelly JP, McNamara M, Connor TJ, Dredge K, Redmond A et al (1999). Activity and onset of action of reboxetine and effect of combination with sertraline in an animal model of depression. Eur J Pharmacol 364: 123-132.

Invernizzi RW, Parini S, Sacchetti G, Fracasso C, Caccia S, Annoni $\mathrm{K}$ et al (2001). Chronic treatment with reboxetine by osmotic pumps facilitates its effect on extracellular noradrenaline and may desensitize alpha(2)-adrenoceptors in the prefrontal cortex. Br J Pharmacol 132: 183-188.

Kovachich GB, Frazer A, Aronson CE (1993). Effect of chronic administration of antidepressants on alpha 2-adrenoceptors in the locus coeruleus and its projection fields in rat brain determined by quantitative autoradiography. Neuropsychopharmacology 8: 57-65.

Li SX, Perry KW, Wong DT (2002). Influence of fluoxetine on the ability of bupropion to modulate extracellular dopamine and norepinephrine concentrations in three mesocorticolimbic areas of rats. Neuropharmacology 42: 181-190.

Linner L, Arborelius L, Nomikos GG, Bertilsson L, Svensson TH (1999). Locus coeruleus neuronal activity and noradrenaline availability in the frontalcortex of rats chronically treated with imipramine: effect of alpha 2-adrenoceptor blockade. Biol Psychiatry 46: 766-774.

Jimenez-Rivera CA, Segarra O, Santacana G, Hoffman T, Savage DD, Weiss GK (1996). Chronic imipramine treatment induces downregulation of alpha-2 receptors in rat's locus coeruleus and $\mathrm{A} 2$ region of the tractus solitarius. Life Sci 58: 287-294.

Millan MJ, Gobert A, Lejeune F, Newman-Tancredi A, Rivet JM, Auclair A et al (2001). S33005, a novel ligand at both serotonin and norepinephrine transporters: II. Behavioral profile in comparison with venlafaxine, reboxetine, citalopram, and clomipramine. J Pharmacol Exp Ther 298: 565-580.

Morilak DA, Blincoe S, Sands SA (1998). Changes in gene expression in the rat locus coeruleus following acute or chronic desipramine or valproate. Soc Neurosci Abstr 24: 1988.

Nelson DR, Pratt GD, Palmer KJ, Johnson AM, Bowery NG (1991). Effect of paroxetine, a selective 5-hydroxytryptamine uptake inhibitor, on beta-adrenoceptors in rat brain: autoradiographic and functional studies. Neuropharmacology 30: 607-616.

Nestler EJ, McMahon A, Sabban EL, Tallman JF, Duman RS (1990). Chronic antidepressant administration decreases the expression of tyrosine hydroxylase in the rat locus coeruleus. Proc Natl Acad Sci USA 87: 7522-7526. 
Ordway GA, Gambarana C, Frazer A (1988). Quantitative autoradiography of central beta adrenoceptor subtypes: comparison of the effects of chronic treatment with desipramine or centrally administered l-isoproterenol. J Pharmacol Exp Ther 247: 379-389.

Ordway GA, Gambarana C, Tejani-Butt SM, Areso P, Hauptmann M, Frazer A (1991). Preferential reduction of binding of 125Iiodopindolol to beta-1 adrenoceptors in the amygdala of rat after antidepressant treatments. J Pharmacol Exp Ther 257: 681-690.

Owens MJ, Knight DL, Nemeroff CB (2000). Paroxetine binding to the rat norepinephrine transporter in vivo. Biol Psychiatry 47: 842-845.

Owens MJ, Morgan WN, Plott SJ, Nemeroff CB (1997). Neurotransmitter receptor and transporter binding profile of antidepressants and their metabolites. J Pharmacol Exp Ther 283: $1305-1322$.

Page ME, Lucki I (2002). Effects of acute and chronic reboxetine treatment on stress-induced monoamine efflux in the rat frontal cortex. Neuropsychopharmacology 27: 237-247.

Paxinos G, Watson C (1986). The Rat Brain in Stereotaxic Coordinates. Academic Press: New York.

Rogoz Z, Kolasiewicz W (2001). Effect of repeated treatment with reboxetine on the central alphal-adrenergic system. Pol J Pharmacol 53: 663-667.

Rush AJ, Ryan ND (2002). Current and emerging therapeutics for depression. In: Davis KL, Charney D, Coyle JT, Nemeroff C (eds) Neuropsychopharmacology: The Fifth Generation of Progress. American College of Neuropsychopharmacology, Lippincott Williams \& Wilkins: Philadelphia. pp 1081-1095.

Sacchetti G, Bernini M, Bianchetti A, Parini S, Invernizzi RW, Samanin R (1999). Studies on the acute and chronic effects of reboxetine on extracellular noradrenaline and other monoamines in the rat brain. Br J Pharmacol 12: 1332-1338.

Sacchetti G, Bernini M, Gobbi M, Parini S, Pirona L, Mennini T et al (2001). Chronic treatment with desipramine facilitates its effect on extracellular noradrenaline in the rat hippocampus: studies on the role of presynaptic alpha2-adrenoceptors. Naunyn Schmiedebergs Arch Pharmacol 363: 66-72.

Sands SA, Guerra V, Morilak DA (2000a). Changes in tyrosine hydroxylase mRNA expression in the rat locus coeruleus following acute or chronic treatment with valproic acid. Neuropsychopharmacology 22: 27-35.

Sands SA, Strong R, Corbitt J, Morilak DA (2000b). Effects of acute restraint stress on tyrosine hydroxylase mRNA expression in locus coeruleus of Wistar and Wistar-Kyoto rats. Brain Res Mol Brain Res 75: 1-7.

Thase ME, Rush JJ (1995). Treatment-resistant depression. In: Bloom FE, Kupfer DJ (eds) Psychopharmacology: The Fourth Generation of Progress. American College of Neuropsychopharmacology, Raven Press, Ltd.: New York. pp 1081-1097.

Thase ME, Rush AJ (1997). When at first you don't succeed: sequential strategies for antidepressant nonresponders. J Clin Psychiatry 58(Suppl 13): 23-29.

Thase ME, Rush AJ, Howland RH, Kornstein SG, Kocsis JH, Gelenberg AJ et al (2002). Double-blind switch study of imipramine or sertraline treatment of antidepressant-resistant chronic depression. Arch Gen Psychiatry 59: 233-239.

Wong EHF, Sonders MS, Amara SG, Tinholt PM, Piercey MF, Hoffmann WP et al (2000). Reboxetine: a pharmacologically potent, selective and specific norepinephrine reuptake inhibitor. Biol Psychiatry 47: 818-829. 